\title{
CONHECENDO OS ALUNOS COM ALTAS HABILIDADES E SUPERDOTAÇÃO COMO CONDIÇÃO PARA UMA EFETIVA INCLUSÃO ESCOLAR
}

\section{Knowing students with high skills and giftedness as a condition for an effective school inclusion}

\author{
Camila Dias Andrade Wenzel ${ }^{1}$ \\ Jacqueline Wanderley Marques Dantas ${ }^{2}$
}

RESUMO: A inclusão escolar é um assunto muito discutido ultimamente entre os educadores, os pais de alunos e a equipe pedagógica escolar. No entanto, quando o público alvo da educação inclusiva é o aluno com Altas Habilidades/Superdotação (AH/SD), grande parte dos docentes desconhece a existência desses alunos no espaço escolar. Tal condição ocorre em virtude do pouco conhecimento que se tem sobre a temática das AH/SD por parte dos professores. Nesse sentido, o presente artigo tem como objetivo apresentar os alunos com $\mathrm{AH} / \mathrm{SD}$ enquadrados na educação inclusiva, por meio da Lei Federal nำ12.796, de 04/04/2013. Este estudo caracteriza-se como uma pesquisa bibliográfica, do tipo revisão de literatura. A reflexão desta temática é de suma importância, pois existem formas de identificação, encaminhamento e Atendimento Educacional Especializado (AEE) para esses alunos. Contudo, percebe-se, na prática, uma escassa informação entre os educadores e a própria escola, no que se refere ao reconhecimento desses educandos e as melhores formas de ensiná-los.

Palavras-chave: Altas Habilidades/Superdotação (AH/SD). Inclusão escolar. Lei Federal no 12.796/2013.

ABSTRACT: School inclusion is a subject much discussed lately among educators, students' parents and the school pedagogical team. However, when the target audience of inclusive education is the student with High Abilities/Giftedness (AH/SD), most teachers are unaware of the existence of these students in the school space. This condition is due to the lack of knowledge about teachers' AH/SD. In this sense, the present article aims to present the students with $A H / S D$ included in inclusive education, through Federal Law №. 12,796, 04/04/2013. This study is characterized as a bibliographical research, of the literature review type. The reflection of this theme is of paramount importance, since there are forms of identification, referral and Specialized Educational Attendance (AEE) for these students. However, there is little

\footnotetext{
Nutricionista e Graduanda em Educação Especial (UNINTER). E-mail: camiladiasandrade@hotmail.com

${ }^{2}$ Mestre em Letras (UFPI). Especialização em Linguística (UFPI). Graduação em Letras Português (UFPI). Graduação em Letras - Espanhol (UESPI). E-mail: jacquelineefilhos2@hotmail.com
}

Cadernos Cajuína, V. 4, N. 1, 2019, p. 58 - 70.

ISSN: 2448-0916 
information in practice between educators and the school itself regarding the recognition of these learners and the best ways of teaching them.

Keywords: High Abilities/Giftedness (AH/SD). School inclusion. Federal Law No. 12,796 / 2013.

\section{INTRODUÇÃO}

O presente trabalho tem por objetivo discutir a temática da educação inclusiva, tratando de forma específica, do reconhecimento das necessidades dos alunos com Altas Habilidades/Superdotação (AH/SD) por parte dos professores, enfatizando a importância da capacitação destes para uma efetiva mudança no processo de escolarização no Brasil, visto que os professores necessitam conhecer as características e particularidades dos alunos com AH/SD, para que possam estar conectados com as concepções que envolvem a escola inclusiva e suas práticas pedagógicas voltadas para o público-alvo.

A questão da inclusão escolar é um assunto novo na sociedade, resultado de lutas e movimentos populares em prol de uma escola inclusiva para todos, movimentos estes que ganharam impulso a partir da Declaração de Salamanca (1994), que defende a escola para todos, sem discriminação, em ambiente integrado. Esse documento faz alusão a uma escola de qualidade para todos e é a favor de uma educação verdadeiramente inclusiva:

El principio rector de este Marco de Acción es que las escuelas deben acoger a todos los niños, independientemente de sus condiciones físicas, intelectuales, sociales, emocionales' lingüísticas u otras. Deben acoger a niños discapacitados y niños bien dotados a niños que viven en la calle y que trabajan niños de poblaciones remotas o nómadas, niños de minorías lingüísticas étnicas o culturales y niños de otros grupos o zonas desfavorecidos o marginados. Todas estas condiciones plantean una serie de retos para los sistemas escolares. En el contexto de este Marco de Acción el término "necesidades educativas especiales" se refiere a todos los niños y jóvenes cuyas necesidades se derivan de su capacidad o sus dificultades de aprendizaje. Muchos niños experimentan dificultades de aprendizaje y tienen por lo tanto necesidades educativas especiales en algún de su escolarización. Las escuelas tienen que encontrar la manera de educar con éxito a todos los niños, incluidos aquellos con discapacidades graves. Cada vez existe un mayor en que los niños y jóvenes con necesidades educativas especiales sean 
incluidos en los planes educativos elaborados para la mayoría de los niños y niñas. Esta idea ha llevado al de escuela integradora. El reto con que se enfrentan las escuelas integradoras es el de desarrollar una pedagogía centrada en el niño, capaz de educar con éxito a todos los niños y niñas comprendidos los que sufren discapacidades graves. El mérito de estas escuelas no es sólo que sean capaces de dar una educación de calidad a todos los niños; con su creación se da un paso muy importante para intentar cambiar las actitudes de discriminación crear comunidades que acojan a todos y sociedades integradoras. (UNESCO, 1994, p. 6)

Com o advento do decreto $\mathrm{n}^{0}$ 7.611, de 17 de novembro de 2011, em conformidade com a Lei Federal ํㅜ 12.796, de 04 de abril de 2013, foi feita a revisão e atualização da LDB no 9.394/96, de 20 de dezembro de 1996, que estabelece as Diretrizes e Bases da Educação Nacional, instituindo, em seu Capítulo $V$ - Da Educação Especial, em seu artigo 58, a nova definição para educação especial.

Art. 58. Entende-se por educação especial, para os efeitos desta Lei, a modalidade de educação escolar oferecida preferencialmente na rede regular de ensino, para educandos com deficiência, transtornos globais do desenvolvimento e altas habilidades ou superdotação. (BRASIL, 1996)

Em seu artigo 59, a LDB descreve como as instituições de ensino deverão proceder com relação aos alunos com deficiência, incluindo-se nesse contexto, os educandos com AH/SD:

Art. 59. Os sistemas de ensino assegurarão aos educandos com deficiência, transtornos globais do desenvolvimento e altas habilidades ou superdotação:

I - currículos, métodos, técnicas, recursos educativos e organização específicos, para atender às suas necessidades;

II - terminalidade específica para aqueles que não puderem atingir o nível exigido para a conclusão do ensino fundamental, em virtude de suas deficiências, e aceleração para concluir em menor tempo o programa escolar para os superdotados;

III - professores com especialização adequada em nível médio ou superior, para atendimento especializado, bem como professores do ensino regular capacitados para a integração desses educandos nas classes comuns;

IV - educação especial para o trabalho, visando a sua efetiva integração na vida em sociedade, inclusive condições adequadas para os que não revelarem capacidade de inserção no trabalho competitivo, mediante articulação com os órgãos oficiais afins, bem como para aqueles que apresentam uma habilidade superior nas áreas artística, intelectual ou psicomotora; 
V - acesso igualitário aos benefícios dos programas sociais suplementares disponíveis para o respectivo nível do ensino regular.

Art. 59-A. O poder público deverá instituir cadastro nacional de alunos com altas habilidades ou superdotação matriculados na educação básica e na educação superior, a fim de fomentar a execução de políticas públicas destinadas ao desenvolvimento pleno das potencialidades desse alunado.

Parágrafo único. A identificação precoce de alunos com altas habilidades ou superdotação, os critérios e procedimentos para inclusão no cadastro referido no caput deste artigo, as entidades responsáveis pelo cadastramento, os mecanismos de acesso aos dados do cadastro e as políticas de desenvolvimento das potencialidades do alunado de que trata o caput serão definidos em regulamento. (BRASIL, 1996)

Percebe-se que, em termos de lei, os alunos com AH/SD estão muito bem amparados, contudo, na realidade, essas condições de uma educação diferenciadora ainda estão distantes de serem confirmadas, pois falta informação por parte dos professores das características dos alunos com AH/SD e, consequentemente, esses alunos se tornam invisíveis para os professores, o que dificulta no desenvolvimento de suas potencialidades.

\section{CONHECENDO OS ALUNOS SUPERDOTADOS}

Sabatella (2008), em seu livro: "Talento e Superdotação: problema ou solução?" pontua que a investigação sobre a natureza e a determinação das características dos alunos com AH/SD tem-se constituído em objeto de muitos estudos.

Com base em classificações internacionais, a definição dos diferentes tipos de superdotados foi utilizada nas orientações do Centro Nacional de Educação Especial do Ministério de Educação (1986), quando se referem à educação especial.

Sabatella (2008), tendo como base as Políticas Públicas da Educação Inclusiva e os documentos orientadores "Saberes e Práticas da Inclusão: Desenvolvendo Competências para Atendimento às Necessidades Educacionais de Alunos com Altas Habilidades/Superdotação" (BRASIL, 2006), apresenta as designações dos alunos com AH/SD, conforme as características específicas de cada um:

Tipo intelectual - Apresenta flexibilidade e fluência de pensamento, capacidade de pensamento abstrato para fazer associações, 
produção ideativa, rapidez de pensamento, elevada compreensão e memória elevadas, capacidade de resolver e lidar com problemas.

Tipo acadêmico - Evidencia aptidão acadêmica específica, atenção, concentração; rapidez de aprendizagem, boa memória, gosto e motivação pelas disciplinas acadêmicas de seu interesse; habilidade para avaliar, sintetizar e organizar o conhecimento; capacidade de produção acadêmica.

Tipo criativo - Relaciona-se às seguintes características: originalidade, imaginação, capacidade para resolver problemas de forma diferente e inovadora, sensibilidade para as situações ambientais, podendo reagir e produzir diferentemente e, até de modo extravagante; sentimento de desafio diante da desordem de fatos; facilidade de auto-expressão, fluência e flexibilidade.

Tipo social - Revela capacidade de liderança e caracteriza-se por demonstrar sensibilidade interpessoal, atitude cooperativa, sociabilidade expressiva, habilidade de trato com pessoas diversas e grupos para estabelecer relações sociais, percepção acurada das situações de grupo, capacidade para resolver situações sociais complexas, alto poder de persuasão e de influência no grupo.

Tipo talento especial - Pode se destacar tanto na área das artes plásticas, musicais, como dramáticas e literárias ou cênicas, evidenciando habilidades especiais para essas atividades e alto desempenho.

Tipo psicomotor - Destaca-se por apresentar habilidade e interesse pelas atividades psicomotoras, evidenciando desempenho fora do comum em velocidade, agilidade de movimentos, força, resistência, controle e coordenação motora (BRASIL, 2006 apud SABATELLA, 2008, p. 81-82).

Conforme Sabatella (2008), os superdotados podem apresentar-se amistosos, extrovertidos, alguns são tímidos e retraídos. Isso contribui para que esse público nem sempre seja reconhecido.

A seguir, segue o quadro com a diferença entre alunos inteligentes e superdotados:

Quadro 1 - Alunos inteligentes e superdotados - diferenças, segundo Galbraith (2000)

\begin{tabular}{c|c}
\hline Aluno inteligente & Aluno superdotado \\
\hline $\begin{array}{c}\text { Sabe as respostas, responde às } \\
\text { perguntas. }\end{array}$ & Faz perguntas, questiona as respostas. \\
\hline É interessado. & É extremamente curioso. \\
\hline Aluno inteligente & Aluno superdotado \\
\hline Presta atenção & Não presta atenção, mas sabe as respostas. \\
\hline Gosta da escola; completa as tarefas. & Gostar de aprender; inicia projetos.
\end{tabular}

Cadernos Cajuína, V. 4, N. 1, 2019, p. 58 - 70. 


\begin{tabular}{|c|c|}
\hline Aprecia companheiros de mesma idade. & Prefere adultos ou companheiros mais velhos. \\
\hline É bom em memorização. & $\begin{array}{l}\text { É bom em supor, adivinhar, levantar } \\
\text { hipóteses. }\end{array}$ \\
\hline Atento, esforça-se e estuda bastante. & $\begin{array}{c}\text { Observador sutil, envolve-se física e } \\
\text { mentalmente. }\end{array}$ \\
\hline Ouve atenciosamente. & Mostra opiniões determinadas. \\
\hline Entende conceitos; é técnico. & Constrói abstrações; é inventor. \\
\hline Satisfeito com sua aprendizagem. & Altamente crítico consigo e com os outros. \\
\hline Procura soluções claras e rápidas. & Explora o problema profundamente. \\
\hline Aprende facilmente. & É entediado, já sabe os conteúdos. \\
\hline Compreende rapidamente. & É extraordinariamente intuitivo. \\
\hline Absorve informações; é receptivo. & Manipula informações; é intenso. \\
\hline Gosta de terminar um projeto. & Desfruta mais o processo do que o produto. \\
\hline
\end{tabular}

Fonte: SABATELLA, Maria Lúcia Prado. Talento e superdotação problema ou solução? 2. ed. Curitiba: Ibpex, 2008, p. 93-94.

Segundo Sabatella (2008), os superdotados são reconhecidos pela superação que apresentam em quase todos os aspectos de comportamento e personalidade, quando comparados a seus pares. Eles normalmente se destacam no seu saber, independente do aspecto, apesar de se considerar que esse saber está mais relacionado para a realização acadêmica. Como diz Sabatella (2008, p. 96) "aprendem muito mais rápido, percebem detalhes e conseguem decodificar o que não foi dito ou escrito".

\section{ESTRATÉGIAS PARA TRABALHAR COM ALUNOS COM AH/SD}

Segundo Sabatella (2008, p. 109):

Os diferentes traços que identificam os indivíduos superdotados correspondem a características psicológicas e habilidades que estão em contínua variação. Essas características existem em níveis distintos, em todos os seres humanos, diferindo em intensidade de indivíduo para indivíduo. Entre os superdotados, as habilidades também se apresentam de modos distintos e, no processo de identificação, precisamos levar em consideração essas variáveis. 
Dados do MEC confirmam que o número de alunos com AH/SD têm crescido nos últimos anos, o que comprova a necessidade de um novo olhar para essa realidade em nossa sociedade.

Figura 1 - Total de alunos com superdotação no Brasil

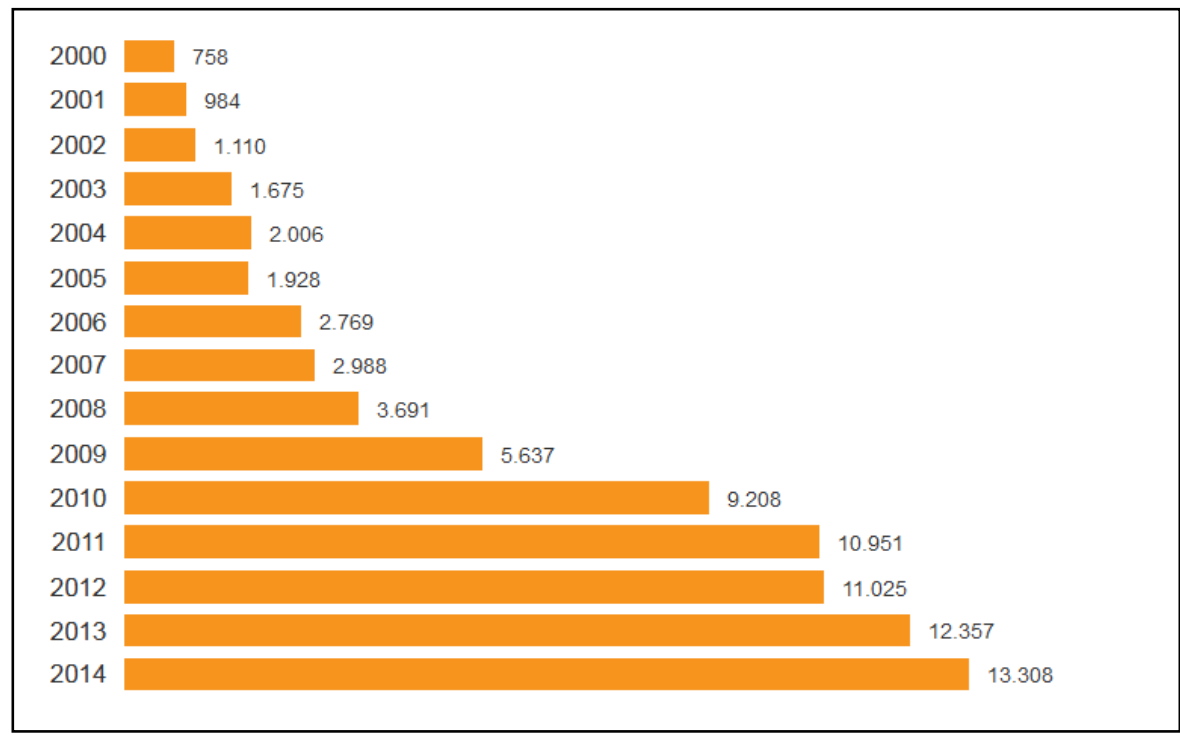

Fonte: https://www1.folha.uol.com.br/cotidiano/2015/10/1695504-numero-desuperdotados-cresce-17-vezes-em-14-anos-nas-escolas-do-pais.shtml

Figura 2 - Total de escolas com alunos com superdotação no Brasil

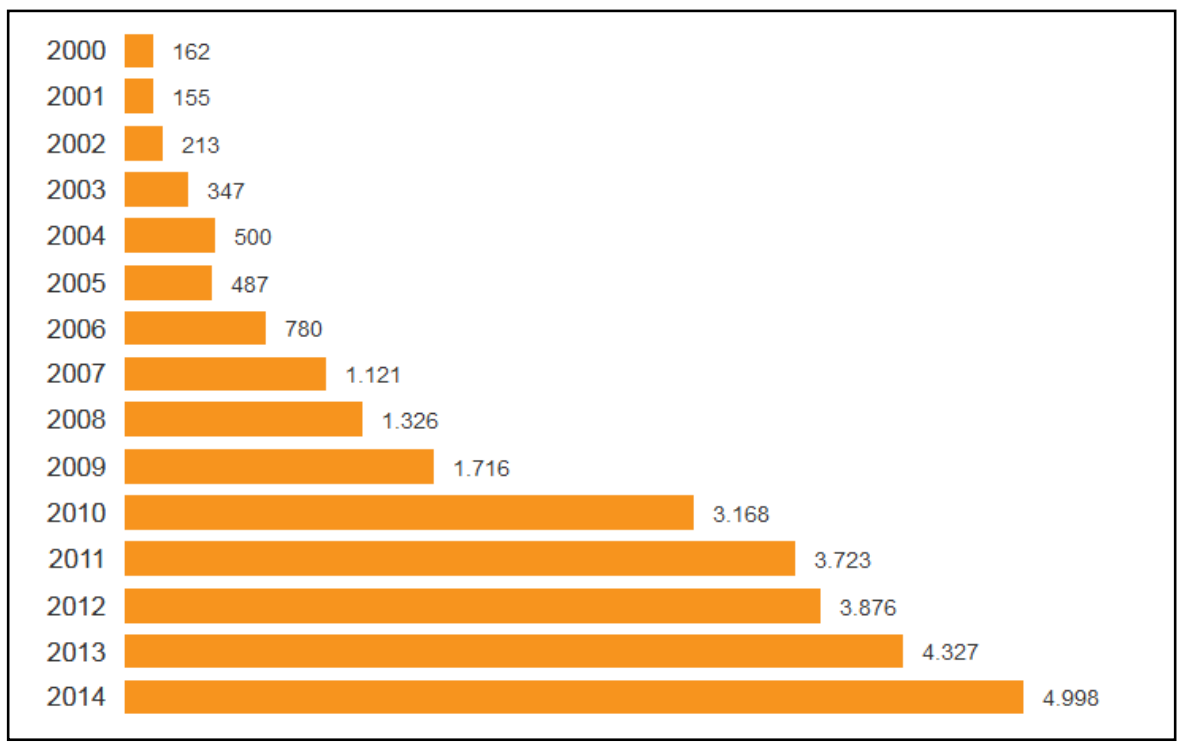

Fonte: https://www1.folha.uol.com.br/cotidiano/2015/10/1695504-numero-desuperdotados-cresce-17-vezes-em-14-anos-nas-escolas-do-pais.shtml 
Uma das concepções amplamente estudadas é o modelo desenvolvido por Renzulli; Smith (1980) apud Sabatella (2008), no qual, a partir da análise de uma amostragem feita com indivíduos criativos e produtivos, foi confirmado que aqueles que se destacam por contribuições significativas mostram um conjunto de três aspectos em que se sobrepõem: habilidade acima da média, criatividade e envolvimento com a tarefa. Segundo Renzulli (1998) apud Sabatella (2008), uma habilidade superior não é considerada um indicativo suficiente; faz-se necessário uma grande motivação para usar a habilidade, devendo ser expressa de modo criativo ou em um grau incomum.

A ilustração do modelo criada por Renzulli (1998) apud Sabatella (2008) é feita por uma figura composta pela interseção de três círculos, chamada de modelo dos três anéis. Considerando-se esse instrumento, uma criança só será indicada para participar de programas para superdotados, quando esses três elementos se sobrepuserem substancialmente.

Figura 3 - Modelo dos três anéis de Renzulli (1998)

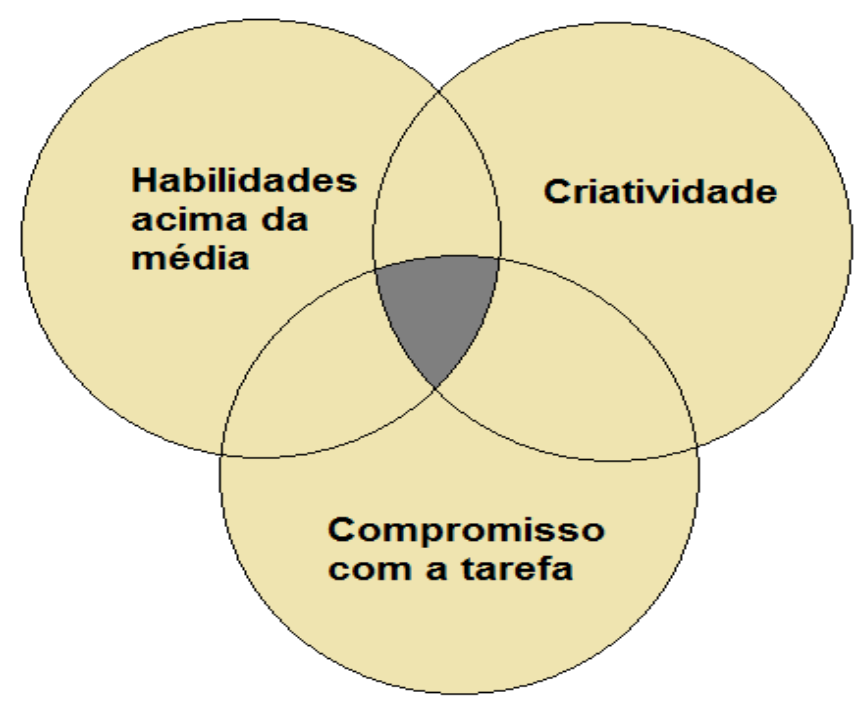

Fonte: SABATELLA, Maria Lúcia Prado. Talento e superdotação problema ou solução? 2. ed. Curitiba: Ibpex, 2008, p. 110.

Os alunos com $\mathrm{AH} / \mathrm{SD}$, mesmo não apresentando dificuldades para aprender em determinadas áreas, necessitam de metodologias ou estratégias de ensino criativas e estimuladoras, que desenvolvam as suas habilidades, contribuindo, dessa maneira, para o acesso e o desenvolvimento acadêmico de modo efetivo e prazeroso.

Cadernos Cajuína, V. 4, N. 1, 2019, p. 58 - 70.

ISSN: 2448-0916 
Porque es evidente que los niños que tienen una buena compresión de los conceptos abstractos y una elevada capacidad de razonamiento necesitan el desafío de actividades que incorporen un 'alto nivel' de habilidad y capacidad de pensamiento. Antes que pedir al niño que simplemente recite o repita lo que ha aprendido, es mejor pedirle que compare, contraste, clasifique, resuma, hipotetice o haga suposiciones. (EXTREMIANA, 2000, p. 102)

Extremiana (2000) pontua que os alunos precisam ser desafiados e estimulados com atividades enriquecedoras para alcançar êxito em sua aprendizagem e desenvolver bem suas potencialidades.

Dessa forma, o ensino deve ser planejado, de maneira complementar ou suplementar pelo professor especializado, buscando fazer uma previsão das necessidades desses alunos e dos meios e recursos disponíveis, estabelecendo objetivos e metas a serem cumpridas pelos educandos de acordo com o desenvolvimento de sua aprendizagem.

Considerando-se o contexto do ensino voltado para uma educação enriquecedora e inclusiva, o professor deve planejar suas aulas de maneira individualizada, implementando as adequações curriculares e respeitando os interesses, potencialidades e modos de aprendizagem dos estudantes, com o objetivo de melhorar o seu rendimento acadêmico.

Baseando-se no Planejamento de Ensino: estratégias estimulantes para o ensino do estudante com altas habilidades ou superdotação, desenvolvido pela Ead.Bauru-SP, apresentamos aqui, os seis princípios propostos por Lewis; Doorlag (1991) e que ajudam o professor no planejamento de suas atividades para alunos com AH/SD.

O primeiro princípio, refere-se ao estímulo à independência, ensinando o estudante a ser "eficiente e efetivo" nas tarefas. Muitas vezes, o estudante permanece preso ao conteúdo regular do ano em que está matriculado. Assim, é interessante que o professor ofereça atividades que estimulem sua curiosidade, buscando novos conhecimentos, a partir de leituras e pesquisas, deixando-o mais livre para seguir seu ritmo que se apresenta mais acelerado.

Estimular os estudantes a utilizar os processos cognitivos complexos ou os processos psicológicos superiores, como pontua Vygotsky (1987), constitui o segundo princípio, que está relacionado ao pensamento criativo, ao planejamento 
consciente e a análise crítica. Atividades oferecidas neste sentido, permitem ao estudante fazer análises de prós e contras em determinadas atividades, exercitando suas habilidades e competências de maneira construtiva, favorecendo seu desenvolvimento acadêmico e cidadão. Os processos psicológicos superiores se referem ao modo de funcionamento psicológico, tipicamente humano, como a capacidade de planejamento, de memória voluntária, imaginação e criatividade entre outras. Esses processos psíquicos são considerados superiores, uma vez que envolvem a intencionalidade; são voluntários e conscientes, possibilitando ao sujeito independência, de acordo com o contexto em que está inserido.

O terceiro princípio, relaciona-se à estimulação dos estudantes para participar de discussões sobre questões, fatos e ideias de maneira ampla aprofundando, gradativamente, o nível de complexidade da análise. Tal procedimento de análise possibilitará ao estudante a tomada de decisões e de comunicação com outras pessoas sobre seus interesses e planos e favorecerá também, as operações de síntese, organização do pensamento e raciocínio lógico, além do planejamento de ações e avaliação de seus efeitos e consequências.

Estimular as habilidades de comunicação interpessoal dos estudantes configura o quarto princípio, pois é fundamental que possam desenvolver as atividades escolares de maneira mais tranquila e harmoniosa com colegas de diferentes faixas etárias e níveis do desenvolvimento cognitivo. Para o estudante com AH/SD, sejam quais forem suas habilidades, poderá apresentar problemas na convivência com seus pares. Nesse sentido, atividades em que possam interagir e comunicar com os outros estudantes devem constar nos objetivos e conteúdos curriculares.

O quinto princípio, refere-se à importância de estimular o estudante no desenvolvimento do respeito pelas pessoas. Os estudantes com $\mathrm{AH} / \mathrm{SD}$, apresentam características peculiares e podem se tornar impacientes com pessoas que funcionam em um nível e ritmo diferente do deles, podendo, inclusive, ter atitudes de desqualificação em relação ao outro. Atitudes como essas, poderão refletir negativamente em sua vida pessoal e social, bem como, trazer consequências destrutivas em seu processo de aprendizagem. Dessa forma, é necessário inserir no planejamento objetivos para o processo. 
Por último, o sexto princípio propõe estimular o desenvolvimento das expectativas positivas do estudante quanto às suas escolhas profissionais, visando ampliar suas possibilidades e otimizando o uso de potencial e habilidades.

Figura 4 - Panorama geral de alunos com AH/SD

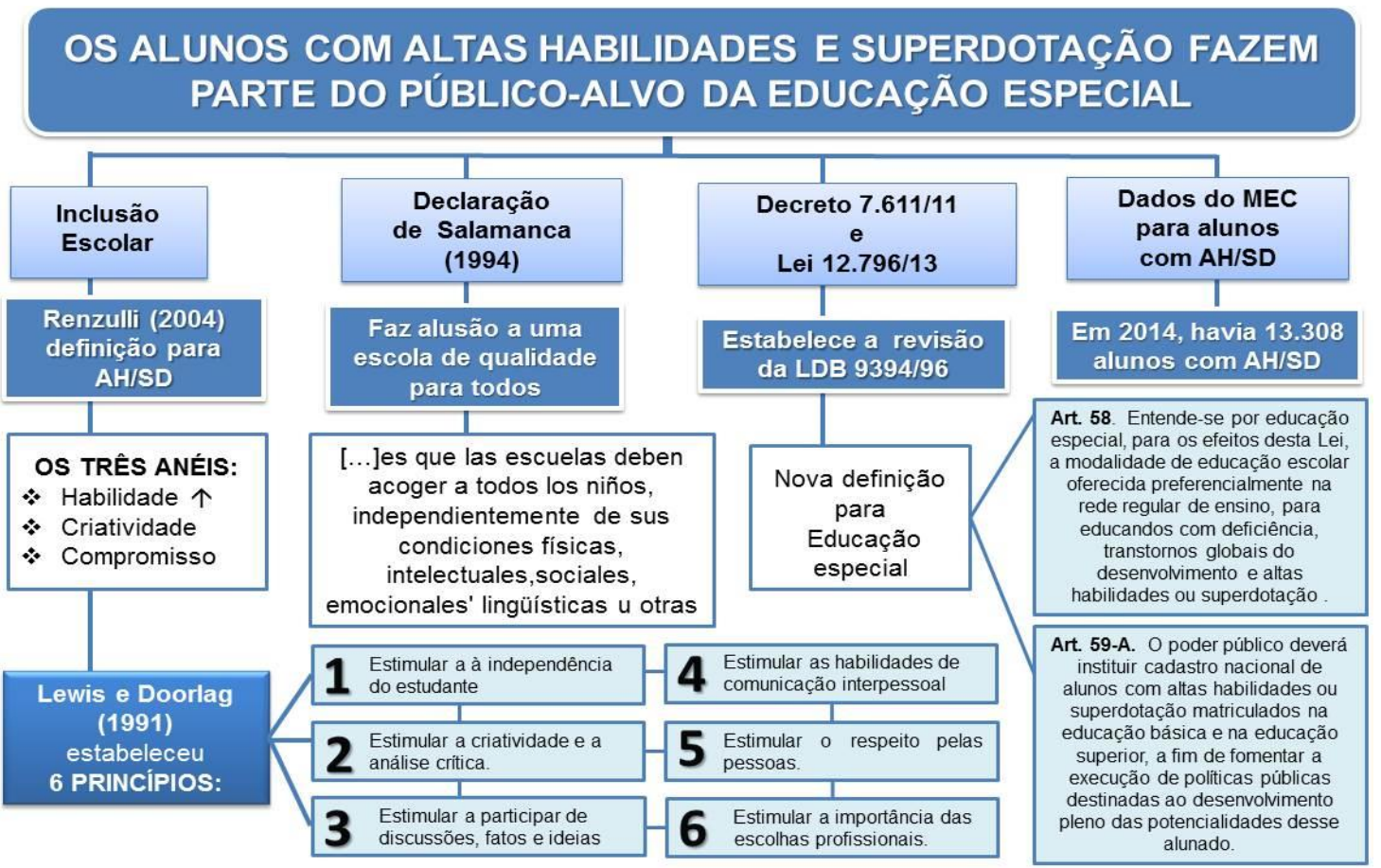

Fonte: Elaborado pelas autoras (2018)

São inúmeras as estratégias de ensino e os recursos didáticos que podem auxiliar o professor em sala de aula, tendo em vista, um ensino significativo e enriquecedor para o desenvolvimento e sucesso dos seus alunos, mas faz-se necessário, acima de tudo, entusiasmo e criatividade por parte do professor para que os seus objetivos sejam alcançados.

[...] a nossa expectativa é que, aplicando bons princípios de aprendizagem para todos os alunos, diluiremos as críticas tradicionais aos programas para superdotados e faremos das escolas locais onde o ensino, a criatividade e o entusiasmo por aprender sejam valorizados e respeitados (RENZULLI, 2004, p. 121).

Como Joseph Renzulli (2004), acreditamos que o professor pode contribuir para o desenvolvimento das habilidades dos alunos, levando-os a manifestar comportamentos de superdotação, desde que planejem bem suas práticas 
pedagógicas, direcionando suas estratégias de ensino para atender às reais necessidades e interesses educacionais dos alunos como um todo, considerando também, nesse contexto, o público dos alunos com AH/SD.

\section{CONCLUSÃO}

Este artigo teve o propósito de permitir uma reflexão e uma discussão sobre a educação inclusiva do aluno com AH/SD, bem como, de pontuar a necessidade de um conhecimento teórico por parte dos professores acerca das AH/SD, no sentido de identificarem as características apresentadas por esses alunos, com o intuito de melhor promover uma educação inclusiva, melhorando e ampliando a aprendizagem dos alunos alvo da educação inclusiva.

Neste sentido, pretende-se por meio deste trabalho que seja possível construir um diálogo fértil entre professores, pais e escola, no que concerne à temática das AH/SD e a inclusão escolar.

\section{REFERÊNCIAS}

BRASIL. Ministério da Educação e Cultura. Saberes e prática da inclusão: desenvolvendo competências para o atendimento às necessidades educacionais de alunos com Altas Habilidades/Superdotação. 2. ed. Brasília: MEC/SEESP, 2006.

Ministério da Educação. LDB - Lei no 9.394, de 20 de dezembro de 1996.

Estabelece as diretrizes e bases da educação nacional. Disponível em: < http://www.planalto.gov.br/ccivil 03/leis/L9394.htm >. Acesso em: 05 set. 2018.

Decreto no 7.611, de 17 de novembro de 2011. Dispõe sobre a educação especial, o atendimento educacional especializado e dá outras providências.

Disponível em: < http://www.planalto.gov.br/ccivil 03/ ato20112014/2011/decreto/d7611.htm >. Acesso em: 05 set. 2018.

Lei no 12.796, de 4 de abril de 2013. Altera a Lei no 9.394, de 20 de dezembro de 1996, que estabelece as diretrizes e bases da educação nacional, para dispor sobre a formação dos profissionais da educação e dar outras providências. Disponível em: < http://www.planalto.gov.br/ccivil 03/ Ato20112014/2013/Lei/L12796.htm >.Acesso em: 05 set. 2018.

. Centro Nacional de Educação Especial/Ministério da Educação e Cultura. Portaria oㅡ 69, de 28 de agosto de 1986. Documenta. n. 310, p. 192-6, out. 1986. 
EAD.BAURU-SP. Planejamento de Ensino: estratégias estimulantes para o ensino do estudante com altas habilidades ou superdotação. Disponível em: < http://ead.bauru.sp.gov.br/efront/www/content/lessons/68/Planejamento\%20de\%20E nsino PDF.pdf >. Acesso em: 05 set. 2018.

EXTREMIANA, A. A. Niños superdotados. Madri: Pirámide, 2000.

GALBRATH, J. You know your child is gifted when... a beginner's guide to life on the bright side. Minneapolis: Free Spirit Publishing, 2000.

LEWIS, R. B.; DOORLAG, D. H. Teaching Special Students in the Mainstream. New York: Macmillan Publishing Company, 1991.

UNESCO. Declaración de Salamanca y Marco de Acción para las Necesidades Educativas Especiales. España, 7-10 de junio de 1994. Disponível em: < http://www.unesco.org/education/pdf/SALAMA S.PDF >. Acesso em: 06 set. 2018.

SABATELLA, Maria Lúcia Prado. Talento e superdotação ou solução? 2. ed. Curitiba: Ibpex, 2008.

RENZULLI, J. S. O que é esta coisa chamada superdotação, e como a desenvolvemos? Uma retrospectiva de vinte e cinco anos. Educação. Tradução de Susana Graciela Pérez Barrera Pérez. Porto Alegre - RS, ano XXVII, n. 1, p. 75 121, jan/abr. 2004.

RENZULLI, J. S. The three-ring conception of giftedness. In: BAUM, S. M.; REIS, S. M.; MAXFIELD, L. R. (Eds.). Nurturing the gifts and talents of primary grade students. Mansfield Center, CT: Creative Learning Press, 1998, p. 50-72.

VIGOTSKY, L. S. Pensamento e linguagem. São Paulo: Martins Fontes, 1987. 